\title{
La reencarnación de lo efímero o cuando las exposiciones universales parían museos ${ }^{1}$
}

\author{
The reincarnation of the ephemeral one or when \\ International Exhibitions Gave Birth Museums
}

\author{
Luis Ángel Sánchez Gómez \\ Departamento de Prehistoria \\ Universidad Complutense de Madrid
}

\section{RESUMEN}

El propósito del artículo es revisar la vinculación existente entre ciertos museos y ciertas exposiciones internacionales durante la segunda mitad del siglo XIX y la primera del XX. Más concretamente, nos centraremos en museos creados de forma directa a partir de materiales o colecciones presentadas en determinadas exposiciones, incluidas algunas de proyección exclusivamente nacional. Los contextos referenciados son la etnología, el colonialismo, las misiones y el folklore.

Palabras clave: Museos, Exposiciones Internacionales, Etnología, Colonialismo, Folklore, Misiones Cristianas.

\section{SUMMARY}

The author focuses on the link that can be documented between some museums and some international exhibitions in the second half of the $19^{\text {th }}$ century and the first one of the $20^{\text {th }}$. We study specifically museums that were created from collections or materials exhibited in certain world's fairs or even in national exhibitions. Our areas of interest are ethnology, colonialism, Christian missions, and folklore.

Key words: Museums, International Exhibitions, Ethnology, Colonialism, Folklore, Christian Missions.

Es probable que la segunda parte del título que antecede suene algo rotunda; sin embargo, creo que resume de forma ajustada el objetivo primordial de estas páginas: acercarnos a las instituciones museísticas nacidas de materiales o de proyectos exhibidores presentados en exposiciones universales, internacionales o coloniales ${ }^{2}$.

\footnotetext{
${ }^{1}$ Estudio enmarcado en el proyecto de investigación "Rituales de dominación y fe: las exposiciones misionales en la era del imperialismo moderno (1851-1958)", dirigido por el autor y financiado por el desaparecido Ministerio de Ciencia e Innovación (ref. HAR2009-08982).

${ }^{2}$ Sólo a partir de 1928, tras la creación de la Oficina Internacional de Exposiciones (http:// www.bie-paris.org), con sede en París, se fijan las normas que determinan la categoría oficial de
} 
También resulta sencillo justificar el uso de la expresión "reencarnación de lo efímero": los museos que revisamos son centros con vocación de permanencia en los que vuelven a tomar vida algunas parcelas o secciones de determinadas exposiciones, eventos estos cuya condición es (salvo contadas excepciones) radicalmente efímera. Una aclaración más: la aproximación que se hace a la interconexión de ambos universos expositivos es necesariamente limitada. Se centra en certámenes y museos europeos, y sólo en los vinculados de forma significativa con la etnología, el colonialismo, las misiones y el folklore. Hablaremos de exposiciones bien conocidas, pero también de otras menos importantes que permiten la creación de museos de interés. Igualmente saldrán a colación museos ya desaparecidos, pero que de una u otra forma cumplen un destacado papel en los contextos referenciados, aunque fuere durante un corto periodo de tiempo ${ }^{3}$.

\section{INTRODUCCIÓN}

Si bien los museos y las exposiciones se desarrollan de forma notable durante el periodo de tiempo considerado (segunda mitad del siglo XIX y primeras décadas del XX), no cabe duda de que las últimas lo hacen de forma mucho más intensa, variada y espectacular. El marcado conservadurismo de la inmensa mayoría de los museos tiene mucho que ver con el academicismo de sus responsables, con los intereses nacionalistas que los acompañan y con el carácter casi sagrado de sus colecciones, mayoritariamente obras de arte y objetos de especial relevancia histórica y arqueológica. Las exposiciones internacionales, aunque comparten con los museos su condición de espacio exhibidor y su vocación nacionalista, son más propicias al cambio, a la innovación en todos los frentes Es cierto que casi todas abren un hueco a la exhibición de objetos tradicionalmente museables (artísticos o de otra condición), pero su esencia es la innovación y la inmensa mayoría de los materiales que presentan se asocian con el progreso de la vida moderna. $\mathrm{Y}$ es precisamente aquí, en el ámbito de la producción industrial, donde surge el primer y más exitoso contexto que abre paso a un museo desde una exposición internacional; en realidad, se trata de un sistema de museos, el primero y más importante creado nunca a partir de un certamen universal. Hablamos de la gran exposición londinense de 1851 (la que asombra al mundo con el Crystal Palace, de J. Paxton) y del asociado barrio museístico que desde 1857 acoge al más importante de sus centros, el South Kensington Museum, fundado ya en 1852 como Museum of Manufactures. A partir de unos inicios

las exposiciones (universales o internacionales) y se ordena el calendario de celebraciones, normas que han sido revisadas en fechas posteriores. Por consiguiente, hasta la década de 1930 son los propios organizadores quienes establecen el calificativo de los certámenes.

${ }^{3}$ El repaso que planteamos tiene un carácter esencialmente empírico, siendo su único objetivo la revisión de las circunstancias inmediatas que vinculan a determinados museos con determinadas exposiciones. Para una propuesta de análisis teórico (quizás en exceso foucaultiana) sobre la interrelación entre museos y exposiciones internacionales durante el siglo XIX, véase Bennett (1996).

${ }^{4}$ La mejor forma de acceder a una información ajustada sobre las principales exposiciones coloniales, internacionales y universales es la obra editada por Findling y Pelle (2008). No obstante, en sus muy numerosos artículos se encontrará escasa información sobre museos. 
relativamente modestos, una inteligente política de adquisiciones transforma y enriquece el museo, reuniendo colecciones domésticas y coloniales que desbordan ampliamente el ámbito de las llamadas "artes decorativas". Su relevancia se acrecienta con nuevos proyectos imperiales, que culminan con la construcción de un grandioso edificio, inaugurado en 1909, que desde entonces acoge al rebautizado como Victoria and Albert Museum. Aunque el nuevo centro se convierte en "the most spectacular repository of the material culture of empire" (Barringer 1998: 27), la singularidad y complejidad de su desarrollo y colecciones hacen recomendable que apartemos al V\&A del eje discursivo de nuestro artículo. Lo anotado implica que dejemos igualmente a un lado el certamen de $1851 \mathrm{y}$ nos adentremos en un marco de relaciones expositivo-museísticas algo diferente que, siendo evidente que bebe de las fuentes del evento londinense, está asociado de forma más directa y acotada con los ámbitos de conocimiento que nos interesan.

\section{MUSEOS ETNOLÓGICOS Y COLONIALES}

La vinculación entre la etnología y el colonialismo parece casi inevitable, pero obviamente no se ha producido siempre o no siempre ha sido relevante. No obstante, aunque la presencia de materiales etnológicos en las exposiciones universales puede ser el resultado de viajes o de alguna otra forma de contacto no intrusivo ni dominante sobre las poblaciones nativas, en la mayoría de los casos tiene su origen en iniciativas de carácter colonial o misional. En numerosas ocasiones la exhibición de esos exóticos objetos no tiene como objetivo el conocimiento de los pueblos referenciados y tampoco el goce estético del espectador. Lo que interesa es atraer la atención del público mostrando el "salvajismo" de esas gentes, al tiempo que se informa sobre la ineludible obligación de "civilizarlos" y sobre los riesgos que comporta la empresa colonial y misional. Pero, como todos estos empeños no se realizan precisamente de forma altruista, lo más habitual es que la presentación de materiales etnológicos se acompañe, tanto de los productos manufacturados que buscan mercados en las colonias, como de las materias primas explotadas en esos exóticos territorios. De esta forma, no son pocos los museos nacidos de este tipo de exposiciones que añaden a su carácter etnológico y colonial una explícita orientación comercial.

\section{AUSTRIA}

Algunos de los primeros museos coloniales abren sus puertas precisamente en territorio colonial (británico); pero las instituciones más interesantes son las que se levantan en las metrópolis. ${ }^{5}$ Especialmente llamativo es el caso de Austria. Aunque, efectivamente, el imperio austro-húngaro tiene una notable proyección política y te-

\footnotetext{
${ }^{5}$ En la obra colectiva editada por Thomas (2010) se incluyen interesantes aportaciones sobre algunos de los más destacados museos coloniales (y/o antropológicos) europeos (creados o no a partir de exposiciones universales o coloniales) y su evolución en un contexto postcolonial. Por su parte, MacKenzie (2010) hace un muy atractivo repaso a algunos de los más significativos museos coloniales británicos levantados en las propias colonias, igualmente al margen de cuáles fueran sus orígenes.
} 
rritorial en la Europa del último tercio del siglo XIX, su condición nada tiene que ver con el colonialismo o el imperialismo ultramarinos. Pero esto no es obstáculo para que el prestigio nacional reclame la ejecución de grandes empresas paracoloniales, como expediciones científicas y proyectos museísticos de hondo calado. Éste es el contexto que hace posible la fundación del Orientalisches Museum (Museo Oriental) de Viena, en 1874, consecuencia directa del éxito de los materiales de Asia y Extremo Oriente exhibidos en la Exposición Universal vienesa de 1873, que a su vez eran parte de los reunidos por una expedición austriaca organizada poco tiempo atrás. En 1886 el centro se reconvierte en el Österreichisches Handelsmuseum (Museo Austriaco del Comercio), aunque conserva casi todas sus colecciones artísticas y etnológicas. Sin embargo, once años después, cuando su director pasa a ocupar ese mismo cargo en el Museum für Kunst und Industrie (Museo de Arte e Industria) —actual Museum für Angewandte Kunst (Museo de Artes Aplicadas)_, se lleva consigo la mayor parte de las colecciones de arte primitivo y oriental, obligando al antiguo centro a fijarse en su faceta educativo-comercial. De hecho, en 1898 se transforma en la Exportakademie, germen de la actual Wirtschaftsuniversität Wien, o Universidad de Economía de Viena.

\section{FRANCIA (I)}

No siempre las colecciones etnológicas presentadas en una exposición internacional acaban teniendo una vinculación tan directa con los intereses comerciales; en ocasiones se asientan sobre proyectos académicos, aunque sea de forma parcial. Esto es lo que ocurre con el certamen universal parisino de 1878, vientre del que surgen dos importantes instituciones vinculadas con el "estudio del hombre" y el conocimiento de los pueblos "exóticos": el Musée d'ethnographie du Trocadéro y el Musée Guimet (actual Musée national des arts asiatiques-Guimet). Las colecciones originales de este último, iniciativa particular del industrial Émile Guimet, se exhiben con extraordinario éxito en aquella exposición; no en vano se trata de forma preferente de impactantes piezas asociadas a religiones asiáticas y orientales, que van mucho más allá de las chinerías y del japonesismo ya por entonces de moda. Pocos meses después del cierre del certamen, en 1879, abre ya sus puertas en Lyón el Museo Guimet; sólo una década más tarde se inaugura la nueva (y actual) sede en la céntrica plaza de Jena de la capital francesa.

El Museo del Trocadero tiene una trayectoria diferente (Dias 1991). Se crea a partir de una importante muestra de materiales etnológicos reunidos por varias "misiones etnográficas" oficiales desplegadas desde mediados del XIX, a los que se suman las piezas que consigue recabar (provenientes de muy diversos centros e instituciones francesas) quien es su principal impulsor, el médico y antropólogo Ernest Hamy. Es tal el éxito que tiene la exhibición de estas colecciones durante el certamen de 1878, que en 1882 reabre sus puertas convertida en institución permanente de carácter oficial, dirigida por el propio Hamy y con sede en el famoso y denostado Palacio del Trocadero, edificio principal de la muestra del 78. Pese a todo, hemos de reconocer que la consolidación del centro no se debe únicamente a la calidad y al interés científico-académico de sus colecciones. A ello contribuye de forma poderosa la atracción del público por todo lo que huela a exótico y, aunque aún de forma tími- 
da, cierta rentabilidad propagandista que de tal despliegue obtiene un Estado (la joven Segunda República) en plena expansión colonial. No obstante, aunque la actividad de Hamy y otros colaboradores es incansable, los fondos para el mantenimiento del museo son escasos, lo que al cabo de algún tiempo hace incluso peligrar la conservación de algunas colecciones. Los problemas tardan años en ser resueltos y, como comprobaremos, lo hacen precisamente gracias a otra exposición internacional: la parisina de 1937.

\section{ESPAÑA}

Aunque comparte con el centro austriaco antes citado una doble orientación etnológica y comercial, el carácter del Museo-Biblioteca de Ultramar — creado en Madrid en 1888 - es muy diferente y, de forma significativa, tampoco se acerca a la perspectiva académica del Museo del Trocadero. Si bien existe alguna tentativa previa, el centro madrileño es la primera (y única) institución museística oficial de tales características fundada en España y su creación es posible porque hereda de forma directa buena parte de las colecciones de la muy exitosa Exposición General de Filipinas, celebrada en Madrid un año antes, en $1887^{6}$. Ciertamente, no es ésta una exposición internacional, sino un pionero certamen nacional especializado en un ámbito, el colonial, que pronto se hace recurrente en tierras europeas y que había tenido su arranque en la Exposición Colonial Internacional de Ámsterdam de 1883. Como ocurre en todos los certámenes de estas características, el objetivo de los organizadores no es precisamente el conocimiento etnológico de los pueblos colonizados, sino el reforzamiento de la imagen de la metrópoli como potencia colonizadora y la intensificación de los vínculos comerciales entre metrópoli y colonia. Así ocurre en la exposición de Madrid, por lo que su núcleo duro debería de haber estar formado por la exhibición de productos y materias primas filipinos destinados a la exportación y por manufacturas peninsulares especialmente apropiadas para su importación desde el archipiélago. En la práctica, sin embargo (y de forma harto contradictoria), acaba teniendo mucho más peso el despliegue de materiales etnológicos, que supera con creces su condición de mero reclamo. Es más, si la exposición atrae como un imán al público madrileño es en realidad por un singular factor añadido que también encontramos en otras exposiciones coloniales (y etnológicas) contemporáneas: la recreación de sendos poblados nativos en el recinto, con estructuras habitables propias de diferentes grupos étnicos del archipiélago en las que, efectivamente, residen durante buena parte del certamen varias decenas de "Salvajes" filipinos.

Tras la clausura del evento, en octubre de 1887, el gobierno acuerda la creación de un centro museístico permanente que habría de servir para favorecer el conocimiento de las colonias que aún conserva España (en el Caribe, el Pacífico y en África) y potenciar los vínculos con la metrópoli, especialmente los comerciales. El nuevo museo tiene como sede el pabellón central de la exposición y asume también la función de biblioteca y centro de documentación sobre Ultramar. En la práctica, sin

\footnotetext{
${ }^{6}$ Sobre la Exposición de Filipinas, véase Sánchez Gómez (2003). Para una revisión general de los museos de etnografía y las exposiciones en la España del siglo XIX, véase Romero de Tejada (1995).
} 
embargo, su condición genérica ultramarina resulta fallida, pues la inmensa mayoría de sus fondos son los legados por el certamen filipino. Por otra parte, tampoco tiene proyección alguna su vertiente aplicada, la económico-comercial. Además (y a diferencia de lo que ocurre en otros museos coloniales europeos), el madrileño carece de cualquier tipo de "atracción" que recuerde los éxitos de la exposición del 87. No se reconstruyen esas viviendas nativas que tanto llamaron la atención y ni siquiera se recurre a los socorridos dioramas que ya por entonces son comunes en exposiciones y museos; de hecho, sus materiales y su diseño expositivo resultan tan adustos como los de cualquier museo etnológico académico contemporáneo. Aunque el centro sobrevive al Desastre del 98, su existencia es a partir de entonces un dramático recordatorio de "tiempos (coloniales) mejores". Cierra sus puertas en 1908, repartiéndose sus colecciones por diferentes museos y bibliotecas de Madrid, aunque es el actual Museo Nacional de Antropología el que guarda la inmensa mayoría de sus antiguos fondos. La que fuera su sede, conocida más tarde como Palacio de Velázquez (por su arquitecto, Ricardo Velázquez Bosco), es hoy un centro de exposiciones temporales dependiente del Museo Nacional Centro de Arte Reina Sofía.

\section{Alemania}

La interacción entre exposiciones y museos en el ámbito alemán sigue cauces realmente singulares. Lo primero que hemos de advertir es que, si existe un país que ha mantenido una relación compleja con el universo de las exposiciones modernas, ése es Alemania. Antes de la unificación, los principales estados alemanes participan de forma destacada y con notable éxito - sobre todo Prusia- en casi todas las exposiciones universales europeas y norteamericanas. Después de 1871, la relevancia de esa presencia se incrementa de modo exponencial, alcanzando su momento de mayor dramatismo en la internacional parisina de 1937, con el literal enfrentamiento entre los pabellones soviético y alemán. Sin embargo, pese a que tanto Prusia como la Alemania imperial (y la nazi) se esfuerzan en proyectar una imagen de Estado moderno e industrializado en todas las exposiciones, no se organiza una gran muestra internacional en territorio alemán hasta las postrimerías del siglo XX (en Hannover, en 2000, y constituye un sonoro fiasco). Pese a todo, en numerosas ciudades alemanas se presentan exposiciones regionales y nacionales durante los luego conocidos como alte gute Zeiten (los "viejos buenos tiempos") del Segundo Reich. Aunque prácticamente todas tienen una orientación industrial, muchas cuentan con una sección colonial singularizada. Así ocurre con la Handels- und Kolonialausstellung (Exposición Comercial y Colonial) que se asocia a la Nordwestdeutsche Gewerbe- und Industrieausstellung (Exposición Industrial y Empresarial de la Alemania Noroccidental) y que tiene lugar en Bremen en 1890. En esta ocasión, las colecciones etnológicas y las figuras y grupos escultóricos de nativos que se muestran tienen tal éxito de público que, aun sin organizarse como museo, se habilitan como exposición visitable hasta $1895^{7}$. Muy poco

\footnotetext{
${ }^{7}$ Parte de los materiales que se exhiben comienzan a ser reunidos en la segunda mitad del siglo XVII, por iniciativa de una asociación de comerciantes convertida más tarde en sociedad científica, llegando incluso a crearse un museo de acceso semipúblico en 1783.
} 
después, en enero de 1896, se constituye formalmente —en un nuevo edificio construido al efecto- el Städtisches Museum für Natur-, Völker- und Handelskunde (Museo Municipal de Historia Natural, Etnografía y Comercio), que es ampliado y convertido en museo estatal en $1933^{\circ}$, trasformado en 1935 en el Deutsches Kolonial- und Übersee-Museum (Museo Colonial y Ultramarino Alemán) y finalmente, en 1951, rebautizado como Übersee-Museum Bremen (Museo Ultramarino de Bremen) (Gawarecki y Seybold 2007). En la actualidad, el museo mantiene (aunque, como es obvio, completamente reformados y modernizados su diseño y su discurso) su triple orientación original: etnológica, naturalista y comercial, si bien esta última no pretende vehicular iniciativas comerciales, sino proyectar recorridos históricos y culturales sobre la historia del comercio ultramarino.

La notable exposición industrial de Bremen de 1890 es claramente superada por la gran Gewerbeausstellung (Exposición Industrial) de Berlín, de 1896, que alcanza unas dimensiones y una relevancia equiparables a la mayoría de las exposiciones internacionales contemporáneas; y lo mismo se puede decir de su extensa sección colonial, a la que se adjudica el calificativo (no del todo ajustado a la realidad) de Erste Deutsche Kolonialausstellung o Primera Exposición Colonial Alemana. En esos prósperos años finales del siglo XIX, Berlín cuenta ya con un extraordinario museo etnológico, el Königliches Museum für Völkerkunde (Museo Real de Etnología, hoy Ethnologisches Museum) ${ }^{9}$. Es ésta una institución de marcado carácter académico fundada en 1873 (aunque retrotrae sus orígenes hasta colecciones reales prusianas del siglo XVII), que tiene como primer director al destacado etnólogo Adolf Bastian y que no se postula (al menos de forma directa) como herramienta gestora de intereses coloniales o comerciales ultramarinos. Es más, en su desarrollo tiene nula incidencia el fenómeno de la exposición internacional y tampoco resulta significativo (en lo que se refiere a la captación de materiales) el colonialismo oficial germano, pues no hemos de olvidar que éste echa a andar en fecha muy tardía, en 1884, y termina pronto y de forma abrupta tras la derrota en la Primera Guerra Mundial. El objetivo del centro es el conocimiento científico de la humanidad (primitiva), de la diversidad de etnias y culturas y, también es cierto, el establecimiento de determinadas jerarquías raciales, todo ello a través de lo que se podría definir como "cosificación" de los denominados "pueblos naturales" (Zimmermann 2001: 172-198). En la citada exposición colonial de 1896, sin embargo, los numerosos materiales etnológicos exhibidos no pretenden articular discursos académicos, sino servir de reclamo sobre el hecho colonial, algo común a todos los eventos de esta condición. Como casi siempre ocurre, el éxito del certamen es enorme, gracias a la ya por entonces típica asociación de exotismo, patriotismo y negocio. Sus promotores (un grupo de empresarios) no pueden ni quieren desaprovechar los réditos del evento, por lo que acuerdan que todas

\footnotetext{
${ }^{8}$ A pesar de la pérdida de las colonias tras la Gran Guerra, el museo permanece abierto, gracias en parte a la iniciativa de una importante comunidad de comerciantes que mantiene vínculos económicos con las antiguas colonias. Luego, a partir de 1933, el museo ve reforzada su situación debido a que el partido nazi convierte a Bremen en la Hauptstadt der Kolonien, la Capital de las Colonias, aunque ya no exista ninguna colonia alemana en Ultramar.

${ }^{9}$ Junto con el Museum für Asiatische Kunst (Museo de Arte Asiático) y el Museum Europäischer Kulturen (Museo de las Culturas de Europa) forma el Museumkomplex Dahlem, instalado en esta zona de la ciudad de Berlín desde 1967.
} 
aquellas colecciones que no deban ser devueltas a sus propietarios sirvan como núcleo original de un Deutsches Kolonialmuseum (Museo Colonial Alemán), que nada tendría que ver con el Museo de Etnología berlinés. Tras algún retraso en el proceso, el museo es inaugurado por el káiser Guillermo II el 13 de octubre de 1899.

El nuevo centro se instala en un edificio de mediano tamaño (hoy desaparecido) y no demasiado acorde para la función museística: el que había ocupado el antiguo Marine-Panoramas, de planta circular, como corresponde a los espacios de exhibición de estos exitosos espectáculos visuales del último tercio del siglo XIX, situado junto a la antigua Lehrter Bahnhof, hoy la gran Hauptbahnhof berlinesa. A pesar de su incómoda configuración, sus responsables ponen en práctica una exposición permanente muy atractiva para el gran público, que sigue casi al pie de la letra el modelo de la exposición colonial (Schneider 1982; Zeller 2002). Así, junto a las clásicas secciones sobre historia, estadística, productos de importación y exportación, higiene, misiones, memorabilia o geografía coloniales (diseñadas de forma más o menos tradicional), la parcela más llamativa y extensa del museo es la dedicada a la recreación de escenarios nativos de los diferentes territorios colonizados, que incluyen chozas indígenas, viviendas de colonos, animales disecados, maniquíes y hasta una pequeña corriente de agua. A pesar de tales atractivos y de que, al parecer, el número de visitantes es relativamente elevado, ya en 1906 los problemas de financiación se hacen patentes, pues los ingresos por entradas no cubren los gastos. Aunque se buscan alternativas y pese a que desde el Museo de Etnología se propone su anexión a este centro - más en calidad de reclamo para ampliar el espectro del público visitante que como fondo museográfico de relieve-, nada se hace al respecto, viéndose obligado a cerrar sus puertas en 1915, cuando ya el imperio colonial alemán amenaza con desintegrarse. Una pequeña parte de sus colecciones es adquirida por el Linden-Museum de Stuttgart (un museo etnológico estatal aún en marcha); el resto parece que pasa a los almacenes del Museo de Etnología de Berlín.

\section{BÉLGICA}

A diferencia de no pocos museos coloniales que son incapaces de sobrevivir a la descolonización, el centro belga al que nos vamos a referir —el Musée Royal de l'Afrique Centrale- sigue vivo y en plena actividad. En esta ocasión, el evento que sirve de útero gestante para el futuro museo es la exposición colonial que tiene lugar en Tervuren, a las afueras de Bruselas, como sección complementaria de la gran exposición universal de 1897; la segunda que tiene lugar en la ciudad en menos de un lustro. Sin duda, estamos ante uno de los eventos coloniales más impactantes —al margen de valoraciones éticas — vistos nunca en Europa (Wynants 1997). Aunque son numerosos los factores que lo singularizan, su componente más espectacular son las tres "villas indígenas" que se levantan, perfectamente ambientadas en entornos de agua y vegetación, y habitadas por casi tres centenares de hombres, mujeres y niños congoleños, que convierten la visita al recinto en una "auténtica aventura". El sentido que tiene todo este montaje (y el de las restantes exposiciones coloniales belgas del XIX) es evidente: se convierte en el más exitoso vehículo con el que cuenta Leopoldo II, el rey de los belgas, para publicitar entre su gente la necesidad de poseer colo- 
nias (aunque esas colonias sean de su real y exclusiva propiedad), presentando de forma espectacular las presuntas riquezas económicas que se podrían obtener de aquellos territorios. El éxito del certamen es tal, que de forma inmediata Leopoldo II plantea la creación de un museo permanente sobre la empresa colonial belga en el Congo. Ante el incremento constante de las colecciones, el edificio original (el pabellón principal de la exposición de 1897) pronto se queda pequeño. Aunque en 1904 el diplomático Roger Casement ha publicado ya su demoledor informe sobre la criminal empresa colonial leopoldina, el monarca no renuncia a su empeño propagandista y ordena la ampliación del centro. El nuevo e impactante edificio (verdadero palacio-museo) se inaugura durante una nueva exposición universal, la de 1910, que igualmente cuenta con una sección colonial en el parque de Tervuren. Curiosamente, en ese momento el Congo ya no es propiedad del rey, pues éste ha vendido a buen precio su antigua posesión al Estado belga. En todo caso, el palacio acoge desde esa fecha el denominado Musée du Congo Belge, que a partir de 1960 — tras la independencia del Congo-, se transforma en el actual Musée Royal de l'Afrique Centrale.

A pesar del cambio de denominación, el museo de Tervuren ha conservado hasta hace pocos años una fortísima impronta colonial y colonialista, gozando de notable predicamento y gran éxito de público ${ }^{10}$. Y esto ha sido así, en primer lugar, porque la empresa colonial belga sigue viva hasta 1960; en segundo, porque (a diferencia de lo ocurrido con el museo ultramarino madrileño) el Museo del Congo hace suyos desde el principio los recursos discursivos y expositivos propios de una exposición colonial; y, en tercero, porque (a diferencia del museo colonial alemán) cuenta con una generosa financiación pública. Aunque, obviamente, el nuevo centro no puede reproducir la "exhibición viva" de los nativos ni recrear sus aldeas, sí muestra en sus ampulosas salas buena parte de lo que se había visto en Tervuren en 1897. Las exóticas y muy llamativas piezas que se exhiben son, como siempre ocurre, un buen reclamo; pero a esto se unen dos factores que refuerzan su interés. De un lado, el museo despliega sugerentes obras de artistas belgas, muchas de ellas destacadas muestras de art nouveau. De otro, en sus salas se pueden contemplar grandes murales e impactantes grupos escultóricos de nativas y nativos africanos que parecen transportar a los visitantes a las lejanas y aún tenebrosas (más aún en el Congo) tierras africanas. Además, la faceta aplicada del museo (el fomento de la explotación económica de la colonia) parece haber gozado de una presencia ajustada hasta el fin del colonialismo belga, que no altera la proyección más espectacular del centro y, al unísono, preserva el lado más comercial del proyecto.

\section{Francia (II)}

De forma aún más intensa que Bélgica, Francia vive en los años de entreguerras un período de auténtico fervor colonial, un fervor que se sustenta no sólo en el orgullo por su grandeur sino en la rentabilidad económica y estratégica que ese inmenso imperio les ofrece. Sin embargo, a pesar de su enorme proyección ultramari-

\footnotetext{
10 Para una revisión crítica de los fondos del museo (editada por el propio centro), véase Wastiau (2000).
} 
na y de haberse organizado desde finales del XIX destacadas exposiciones coloniales (en Lyón, París o Marsella), el Estado francés no dispone aún de un gran centro académico-museístico nacional sobre su imperio ${ }^{11}$; un centro que sirviera (como ocurría con el Museo del Congo de Bruselas) para mostrar su poder, reforzar el apoyo de la población a la empresa colonial y canalizar el conocimiento y explotación de las tierras y gentes de tan exóticas posesiones. Precisamente éstos son los objetivos que justifican la organización en París, en 1931, de la gigantesca Exposition Coloniale Internationale et des Pays d'Outre Mer, la mayor que se haya organizado nunca en Europa. Y, como verdadero epicentro del certamen, el llamativo Palais de la Porte Dorée acoge el inicialmente llamado Musée permanent des colonies, título que informa ya sobre el proyecto de continuidad que han ideado sus organizadores.

Los planes se cumplen y, tras la clausura de la exposición, el nuevo museo comienza su andadura como institución independiente. Muy pronto, en 1935, cambia su nombre por el de Musée de la France d'Outre-mer, más adecuado para unos años en los que se proyectan ciertas transformaciones en el contexto colonial. Con una u otra denominación, el nuevo centro permite por fin vehicular en clave formativa la grandeur imperial gala. El edificio que lo acoge (el creado para la exposición) es llamativo por su modernidad y pureza de líneas pero, más aún, por los impactantes relieves exotistas (y enaltecedores de la empresa colonial) que cubren sus fachadas. Algo similar ocurre en su interior, donde destacan de forma poderosa los enormes y coloristas murales de temática colonial. En lo que se refiere a la presentación de sus colecciones, tanto durante la exposición como ya en calidad de museo, el nuevo centro no resulta demasiado innovador, aunque sí puede presumir de parafernalia colonial. Al margen de pinturas, banderas y emblemas, lo más llamativo siguen siendo los materiales etnológicos y los dioramas (tanto de temática exotista como histórica), a los que se suma el nuevo contexto de admiración que se genera en torno al denominado "arte negro" (L'Estoile 2001; Hodeir 2002). Además, el centro se asegura la visita del público gracias a unos complementos muy atractivos: una enorme sala de cine, un gran planisferio luminoso y un espectacular acuario. Sin embargo, pese a tan llamativo despliegue de medios, la pedagogía colonial-imperial del museo sobrevive como tal durante poco más de dos décadas, hasta que el arranque de los procesos de descolonización fuerza la reorientación ideológica del centro. Así, en la década de 1960 se convierte en Musée des arts africains et océaniens; en Musée national des Arts d'Afrique et d'Océanie en 1990; y finalmente (tras el traslado de sus fondos al Musée du quai Branly) desde 2007 es sede de la Cité nationale de l'histoire de l'immigration que, a su vez, acoge al Musée de l'histoire et des cultures de l'immigration. Pese a todo, los llamativos relieves de sus fachadas hacen imposible olvidar cuáles fueron los orígenes de la institución.

Pero la existencia de un gran museo colonial en la Francia de los años 30 no cierra el paso a otras instituciones centradas en el estudio "del hombre"; de hecho, un nuevo certamen amplía de forma considerable el espectro museístico antropológico galo. Nos referimos a la Exposition International des Arts et des Techniques dans la vie moderne, celebrada también en París, en 1937, la última de rango internacional organizada hasta la actualidad en territorio francés. Se pone en marcha en un mo-

\footnotetext{
${ }^{11}$ El avejentado Museo del Trocadero no cumple con tales expectativas.
} 
mento marcado por la tensión política internacional y la amenaza de la guerra, circunstancias que obligan a los organizadores a reforzar los tradicionales mensajes de paz articulados en casi todas las exposiciones internacionales. Lamentablemente, resulta un rotundo fracaso en cuanto que mecanismo para apaciguar la locura racialimperialista nazi, y nada puede hacer para evitar el dramático conflicto bélico que estalla sólo un par de años después. En cualquier caso, el certamen es el lugar adecuado para seguir apostando por la grandeur de la patrie, lo que explica la presentación de varios proyectos museológicos de hondo calado ${ }^{12}$. En el ámbito antropológico nos encontramos con el rediseño y la reinstalación del antiguo Museo del Trocadero, exitoso empeño de Paul Rivet, que será su primer director y personaje de extraordinaria relevancia en la investigación etnológica del país. Curiosamente, la exhibición original y el subsiguiente Musée de l'Homme (denominación del nuevo centro) se levantan en los mismos terrenos que acogieran al vetusto Museo del Trocadero; pero ahora, en 1937, el antiguo y ecléctico edificio ha dejado paso al Palais de Chaillot, una de cuyas alas ocupa casi por entero el nuevo centro, que, a las antiguas colecciones etnológicas del Trocadero, suma las de antropología física y prehistoria del Museo nacional de historia natural y algunos materiales etnológicos exhibidos en la exposición colonial de 1931. A diferencia de su predecesor, el Musée de l'Homme cuenta con los recursos suficientes para mantener una intensa actividad, que combina su condición de museo con la de centro holístico de investigación en ciencias antropológicas, acogiendo a personajes tan destacados como Claude Lévi-Strauss, Marcel Griaule, Michel Leiris, o André Leroi-Gourhan. Lamentablemente, en 2003 el museo cierra sus galerías etnológicas (hoy el centro está cerrado en su totalidad), dando comienzo así a un proceso de transformación que debería culminar en 2014; en cualquier caso, todos esos fondos etnológicos han pasado a formar parte del impresionante, carísimo y discutido Musée du quai de Branly, inaugurado en 2006. El remodelado Musée de l'Homme centrará sus contenidos y actividad en la antropología física y la prehistoria, aunque parece que también dispondrá de los materiales etnológicos incorporados a partir de $2003^{13}$.

\section{MUSEOS MISIONALES}

Antes de abordar el estudio del último bloque museístico-expositivo que nos interesa (sobre el folklore y las costumbres populares), vamos a comentar un certamen más,

\footnotetext{
${ }^{12}$ Además de los comentados en el texto, esta exposición da origen de forma directa a otros dos importantes museos. De un lado, al Musée National d'Art Moderne, inaugurado en 1947 y de no muy larga vida, pues sus colecciones más recientes se transfieren al Centre Georges Pompidou en 1977, mientras que las anteriores a 1870 lo hacen, en 1986, al Musée d'Orsay. El resto da forma al Musée d'Art Moderne de la Ville de Paris, aunque no abre como tal hasta 1961. El otro gran museo derivado de aquel certamen es el llamado Palais de la Découverte (un museo dedicado a las ciencias), que continúa en su emplazamiento original, el Palais d'Antin, en realidad una parte del Grand Palais de la Exposición Universal de 1900.

${ }^{13}$ Para una muy interesante revisión de la gestación, desarrollo y desaparición del Musée de l'Homme (enmarcada en un extenso e incisivo estudio sobre la representación museográfica del "Otro" en Francia), véase L'Estoile (2010).
} 
dedicado al exótico y lucrativo universo de las colonias. No obstante, no se trata de un evento colonial, sino de una exposición misional, la más importante del orbe católico y la más rica en términos museográficos de las celebradas por las Iglesias cristianas. Hablamos de la gran Exposición Misional Vaticana de 1925 (Sánchez Gómez 2007).

Las exposiciones misionales (mejor etnológico-misionales) se documentan durante la segunda mitad del XIX y la primera del XX, si bien tienen su momento de apogeo en los dos últimos decenios del primero, los años previos a la Primera Guerra Mundial y las décadas de 1920 y 1930. Se asocian, obviamente, a los afanes de implementar nuevas y más eficaces modalidades de propaganda misional, pero su aparición y desarrollo sólo se pueden comprender si valoramos su compleja y, en ocasiones, contradictoria vinculación con dos fenómenos históricos coetáneos de extraordinaria relevancia: la intensificación del imperialismo colonialista de Occidente y la eclosión y casi inmediata consolidación del fenómeno de la exposición internacional. Aunque tanto las Iglesias protestantes como la católica participan en algunas exposiciones internacionales y coloniales (en éstas últimas más las católicas, y ya en la época de entreguerras), no siempre es fácil o conveniente esa vinculación. Se opta así por la organización de exposiciones misionales autónomas, empeño que abordan ya desde mediados del XIX las Iglesias protestantes británicas. Roma tarda décadas en reaccionar, aunque al final se resarce con creces del tiempo perdido.

La exposición misional vaticana de 1925 es el mejor ejemplo de lo apuntado. En este gigantesco certamen las diferentes órdenes, sociedades y congregaciones católicas vinculadas con la obra misional presentan información y materiales sobre su pasado, su presente y sus proyectos de futuro, tanto en relación con la empresa evangelizadora como con las tareas de carácter asistencial y "civilizador". En esta ocasión, como en todas pero ahora a una escala mucho mayor, el reclamo principal es la exhibición de llamativos objetos de los pueblos "salvajes" (y de los exóticos orientales) ya misionados o de los que aún han de ser cristianizados. El número de piezas que se despliega es enorme, más de setenta mil, y entusiasta la respuesta del público: durante los casi trece meses que permanece abierta, la exposición recibe alrededor de un millón de visitas ${ }^{14}$. Pues bien, este certamen también acaba dando origen a un importante centro museístico: el Museo Misionero-Etnológico del Vaticano, que se inaugura el 1 de febrero de $1927^{15}$. Es un museo que, sin ser colonial, surge de una actividad (las misiones) favorecida y hasta auspiciada por el colonialismo, y a partir de un formato exhibidor original inspirado claramente en las exposiciones coloniales. Todo ello hace que el nuevo centro reproduzca ciertos rasgos característicos

\footnotetext{
${ }^{14} \mathrm{El}$ elevado número de visitantes tiene mucho que ver con el hecho (perfectamente calculado por el Vaticano) de que 1925 es Año Santo.

${ }^{15}$ Una parte importante de las colecciones presentadas en la exposición procede del Museo Borgia (de la congregación Propaganda Fide), que desaparece con la creación del nuevo museo vaticano. Sobre este último, véase Wates (2005). También ofrece alguna información de interés un breve texto de Zerbini (2004). Tras su participación en la exposición vaticana, algunas órdenes católicas destinan parte de las colecciones allí expuestas a la creación (o ampliación) de pequeños (o no tan pequeños) museos misionales, sobre todo en Italia (Musei 2007). Algo similar ocurre (en relación con el ámbito español) tras la celebración de la gran Exposición Misional Española, que se organiza durante la Exposición Internacional de Barcelona de 1929 (Sánchez Gómez 2007).
} 
de los museos coloniales (contexto de dominación, superioridad racial, paternalismo...), aunque es cierto que su interpretación de las diferencias raciales queda atemperada por el monogenismo y el humanismo cristianos. Por otra parte, no hemos de olvidar que el objetivo inicial del museo es (como lo fue el de la exposición) llamar la atención sobre las misiones, ensalzar la obra del misionero, recabar nuevos apoyos para la obra misional futura y, por supuesto, demostrar la irrenunciable obligación de continuarla presentando la desvalida (cuando no depravada) condición espiritual y material de los pueblos "primitivos" o paganos aún no cristianizados.

Los procesos de descolonización y los cambios más o menos intensos operados en el seno de la propia Iglesia católica durante el siglo XX no parecen haber encajado bien con la esencia original del museo, aunque tampoco han posibilitado reconducirlo con determinación por otros cauces. De hecho, la trayectoria del centro ha sido y continúa siendo algo errática. Hasta 1968 tiene su sede en el Palacio de Letrán; en 1974, y tras unos años de cierre, reabre sus puertas en la actual sede del Vaticano, aunque desde entonces el acceso a los fondos ha estado interrumpido en numerosas ocasiones, cuando no cerrada la totalidad del museo. En 2006 reabre parcialmente sus instalaciones, aunque sólo para la organización de exposiciones temporales que, eso sí, están dando a conocer al menos una parte de sus muy interesantes colecciones.

\section{MUSEOS DE FOLKLORE}

Los primeros museos de folklore combinan una orientación anticuarista con cierta inspiración etnológica y un evidente propósito de reivindicar o fortalecer unas supuestas esencias identitarias nacionales, vinculadas siempre con "el pueblo" y "lo tradicional". Curiosamente, pese a asumir tan patriótico rol, no todos los Estados europeos (ni lo más poderosos) ponen en marcha museos nacionales de folklore durante los años finales del XIX y comienzos del XX. De hecho, se desarrollan inicialmente en un área excéntrica, en el ámbito escandinavo, donde el "patrimonio tradicional" es más relevante como símbolo de identidad que su relativamente escaso patrimonio monumental. Algunos de estos museos se replantean pronto sus diseños expositivos, abriendo paso a la instalación de escenas y grupos figurativos y, en último término, a la aparición del "museo al aire libre", que combina sin complejos y con decidida vocación educativa (pero también espectacular) la autenticidad del objeto "original" con las ambientaciones, los decorados y los maniquíes. Y es precisamente aquí, en relación con estas dos innovaciones, donde entran en juego las exposiciones internacionales.

\section{ESCANDINAVIA}

El escenario que acoge ese inicial y fructífero contexto de interacción entre las exposiciones internacionales y los museos de folklore nórdicos lo encontramos en la gran Exposición Universal parisina de 1867. En esta ocasión, y a diferencia de lo que ocurre en otros contextos, lo reseñable no es la presentación de unas colecciones etnológicas que sirven de origen a un futuro museo. Lo que se documenta en ese exitoso y complejo evento es algo inicialmente más simple, pero que acaba teniendo 
una gran trascendencia en el mundo de la museografía: varias escenas o dioramas de la vida rural escandinava, incluido el mundo de los lapones, que se pueden visitar en el pabellón de Suecia (Stoklund 1994). En realidad, la presentación de estos grupos escultóricos (adecuadamente ambientados) no responde a una iniciativa particular de los expositores escandinavos, sino que es la respuesta a una petición hecha por los organizadores del certamen para la exhibición de elementos de lo que hoy calificaríamos como cultura material del mundo rural, muy especialmente su indumentaria, todo ello inspirado por el profundo humanismo reformista que singulariza a este certamen y acorde con la orientación ideológica que otorga a la exposición su máximo responsable: el sociólogo, ingeniero y economista francés Frederic Le Play. La respuesta es muy positiva, pues se muestra un buen número de maniquíes y grupos escultóricos de diferentes provincias francesas y de otros quince países europeos. Sin embargo, la proyección museográfica (casi inmediata) de ese nuevo recurso expositivo se queda en territorio escandinavo, concretamente en Suecia. Allí, en Estocolmo, el destacado folklorista y museógrafo Artur Hazelius funda en 1873 la inicialmente denominada Skandinavisk-etnografiska samlingen (Colección Etnográfica Escandinava), convertida en Nordiska Museum en 1883 y más tarde en el actual Nordiska museet (Museo nórdico). Las escenas de folklife que acoge el nuevo centro son una de las claves de su filosofía, empeñada en el conocimiento de las esencias nacionales y en su proyección educativa, circunstancias que resultan más relevantes para el responsable del museo que la conservación y exhibición (hasta entonces prácticamente sacralizada) de piezas "auténticas" y "originales". Anotemos, por otra parte, que el impactante edificio actual del Nordiska museet (Museo nórdico), aunque no se da por concluido hasta 1907 (y sólo con un tercio del volumen originalmente diseñado), se construye para albergar las colecciones museográficas nacionales exhibidas en otro certamen internacional; en este caso la Exposición de Estocolmo de 1897.

La interacción de Hazelius con las exposiciones internacionales continúa en Viena (1873), Filadelfia (1876) y, sobre todo, en París (1878), donde presenta parte de sus colecciones y grupos escultóricos. El éxito es enorme y pronto su modelo de montaje museográfico se extiende por otras tierras escandinavas, siendo fuente de inspiración para el primer museo al aire libre del mundo: la colección etnográfica y de arquitecturas tradicionales noruegas del rey Óscar II, que abre sus puertas al público en Cristiania (actual Oslo) en 1881 y que años después, en 1907, acaba siendo absorbida por el Norsk Folkemuseum (Museo de Folklore Noruego), fundado en 1894. Sin embargo, aunque es en Noruega donde por vez primera se pone en marcha un museo al aire libre, de nuevo es en Suecia donde el complejo mundo museográficofolklórico nórdico se enriquece con una creación realmente espectacular. Hablamos de Skansen, un magnífico complemento del Nordiska museet que hoy continúa siendo un auténtico referente para todos los museos etnológicos al aire libre del mundo y que el propio Artur Hazelius funda en Estocolmo, en 1891, tras una visita a la colección etnográfica real de Cristiania.

\section{EUROPA CONTINENTAL}

El modelo de museo al aire libre se extiende pronto por tierras nórdicas y algo 
más tarde por buena parte del centro y el este de Europa. En Alemania alcanza un gran protagonismo; de hecho, el término alemán que lo denomina (Freilichtmuseum) es cada vez más empleado para identificar esta tipología de museo. Los países occidentales, y más aún los mediterráneos, quedan casi completamente al margen del proceso, que sólo se recupera (en algunos casos) a partir de finales de los años 60, gracias al fenómeno del ecomuseo. No obstante, durante el periodo de entreguerras, con los movimientos políticos nacionalistas en plena expansión, las exposiciones internacionales vuelven a ser caldo de cultivo para la generación de un nuevo modelo de museo, que en este caso debe servir de receptáculo para la preservación y proyección de las presuntas esencias patrias; unas esencias surgidas primordialmente del mundo rural tradicional. Es cierto que los museos de folklore nórdicos del XIX tienen un similar objetivo identitario y nacionalista; sin embargo, los que surgen en el periodo de entreguerras presentan rasgos claramente diferenciados. Sobre todos ellos se proyecta una carga ideológica más intensa: en unos, se vuelca hacia posiciones claramente fascistas y ultranacionalistas; en otros, tiene connotaciones frentepopulistas. Vamos a comentar cuatro exposiciones que dan origen a otros tantos museos de folklore: dos se organizan en España, una en Francia y la última en Portugal. Los casos españoles son los más atípicos y los que tienen consecuencias menos relevantes en clave museográfica, al menos visto el asunto desde cierta perspectiva. El ejemplo francés es el más interesante e innovador; el portugués es igualmente moderno, pero lo significativo es que se presenta como la más acabada muestra de manipulación política (fascista) de las "artes y tradiciones populares" de una nación.

\subsection{España}

El primer ejemplo español es especialmente singular, ya que el certamen del que surge no es una exposición internacional; ni siquiera se puede decir que se trate de una exposición nacional "típica", es decir, de orientación industrial o comercial. Se trata de la Exposición del Traje Regional e Histórico, que tiene lugar en Madrid en 1925. España vive entonces bajo la dictadura del general Primo de Rivera. Al margen de otras muchas cuestiones, son años de política autoritaria en los que tradición, religión nacional-católica y conservadurismo marcan el ritmo vital de la sociedad. En este contexto, se diseñan proyectos que pretenden reforzar los presuntos rasgos propios de la identidad hispana, en los que colaboran políticos, intelectuales, artistas y hasta algunos elementos "ilustrados" de la nobleza. Entre todas las iniciativas que se ponen en marcha, una de las más destacadas es la exposición del año 25, que reúne (en el antiguo Palacio de Bibliotecas y Museos de Madrid, hoy edificio compartido por la Biblioteca Nacional y el Museo Aruqeológico Nacional) un amplísimo catálogo de prendas de indumentaria históricas y tradicionales, complementado con un buen número de fotografías y acuarelas.

El éxito de la exposición, que inauguran los Reyes de España, es enorme, debido tanto a la variedad, riqueza y espectacularidad de las piezas exhibidas como al atractivo diseño museográfico que pone en práctica su director técnico, el antropólogo Luis de Hoyos Sáinz. Y, como ya ocurriera en los museos nórdicos de fines de siglo, en ese diseño juega un papel fundamental la recreación de ambientes, que ahora se 
muestran mucho más elaborados, pues integran amplios espacios arquitectónicos (interiores de viviendas, patios y calles) y gran número de maniquíes, todos ellos bien trabajados desde el punto de vista artístico, ricamente ataviados e interactuando de forma coherente y armoniosa en sus respectivos cuadros escénicos. Otra cuestión relevante de la exposición es que desde un principio existe la intención de transformarla en museo, ya que buena parte de las colecciones han sido adquiridas por el Estado y otras muchas son o acaban siendo donadas por sus propietarios. La idea sale efectivamente adelante, creándose en 1927 un patronato que habría de diseñar y organizar el futuro Museo del Traje Regional e Histórico. Sin embargo, el tiempo pasa y el museo sigue sin disponer de sede. En 1932, ya en el periodo republicano, comienzan a darse los primeros pasos en una nueva dirección, la defendida por Luis de Hoyos, quien desde tiempo atrás (antes de la exposición) venía reclamando la necesidad de crear un museo que fuera más allá de un mero interés histórico-artístico o folklorista sobre el traje. Al final, lo consigue. Con fecha de 26 de junio de 1934 el gobierno de la Segunda República española decreta la creación del único museo nacional que nace bajo su bandera: el Museo Nacional del Pueblo Español. Curiosamente, los materiales que habían servido a la dictadura para definir las esencias hispanas son los mismos que ahora utiliza la República para, como dice su decreto fundacional, saldar "la deuda cultural y política contraída [...] con el Pueblo Español" (Mingote 2011).

Desgraciadamente, la historia del museo no es demasiado afortunada. La Guerra Civil interrumpe los intensos trabajos que se venían realizando y supone la retirada de Hoyos de la dirección. Tras múltiples avatares, el centro abre por fin sus puertas ¡en 1971!, en el actual Palacio del Senado, en un momento cronológico y en un contexto político y social muy diferentes a los de su gestación. En cualquier caso, en 1973 ya se ha visto obligado a cerrar ${ }^{16}$. A partir de entonces, deja de ser accesible al público. En 2004, una pequeña parte de sus fondos (de indumentaria histórica) se incorpora a la exposición permanente del nuevo Museo del Traje, con sede en el edificio del antiguo Museo Español de Arte Contemporáneo, en la Ciudad Universitaria de Madrid. El resto de sus numerosas, variadas y muy ricas colecciones continúa almacenado en los depósitos. Y, teniendo en cuenta la incertidumbre de los planes para la creación de un pretendido Museo Nacional de Etnografía, puede que así permanezcan por los siglos de los siglos...

Sin salir de España tenemos otro ejemplo de certamen que da origen a una muy singular exposición permanente, pues de eso se trata y no de un museo. Me refiero a la Exposición Internacional de Barcelona de 1929. El catalán es sólo uno de los dos eventos inaugurados en 1929 bajo la denominación oficial de "Exposición General de Españan; el otro es la Exposición Iberoamericana de Sevilla. En el reparto, Sevilla se queda con una singular exposición que oscila entre lo nostálgico y lo neocolonial; por su parte, Barcelona pone en marcha una verdadera (y exitosa) exposición internacional. Sin embargo, a pesar del despliegue de tecnologías, de la espectacular imagen que ofrece el Palacio Nacional de Montjuïc con sus grandes proyectores, de los hipnotizantes juegos de agua y luz de sus fuentes monumentales y de la modernidad del Estadio Olímpico, el certamen no renuncia a otros recursos

\footnotetext{
${ }^{16}$ En alguna fuente se anota que sólo abre durante unos meses en 1973.
} 
menos sofisticados pero tanto o más efectivos. Y claro, en un momento de tan hondo españolismo como el que se vive en los años de la dictadura primorriverista (y pese a desarrollarse en Cataluña), los organizadores del certamen ofrecen al público visitante, sobre todo al internacional, aquello que todo turista espera disfrutar: las tradiciones y el tipismo de lo "auténticamente español". Se crea así el famoso Pueblo Español que, pese a su inicial carácter efímero, se ha conservado hasta la actualidad. No obstante, aunque hemos anotado que la defensa de lo español y de la "españolidad" (incluida la de Cataluña) articula en buena medida la esencia de esa recreación, debemos reconocer que la idea original es previa a la dictadura, y que se enmarca en la amplia tradición de reconstrucción histórica y folklórica de arquitecturas presente en numerosas exposiciones internacionales desde el último tercio del siglo XIX, sobre todo francesas y belgas.

El Pueblo Español (Poble Espanyol, en catalán) ocupa una superficie de 23.000 metros cuadrados que, sin ser extraordinaria, es lo suficientemente extensa para acoger la reproducción de ciento diecisiete unidades arquitectónicas: viviendas, iglesias, estructuras monumentales, calles y plazas; todo ello articulado a modo de población rural que, pese a la diversidad de estilos, resulta tan atractiva como interesante, y no sólo en clave turística ${ }^{17}$. La razón de su éxito la encontramos en la intensa labor de documentación previa llevada a cabo (sobre el terreno) por los dos arquitectos, el crítico de arte y el artista responsables de su diseño y construcción: Ramon Reventós, Francesc Folguera, Xavier Nogués y Miquel Utrillo, respectivamente. El objetivo de sus responsables no es reunir un elenco de los principales monumentos del país, sino combinar una selección de arquitecturas históricas y tradicionales que reflejen de forma coherente y plástica la diversidad y riqueza arquitectónicas de España. El resultado es extraordinario. Durante el periodo de apertura de la exposición, el recinto del Pueblo Español conjuga de forma exitosa una muy fiel reproducción de arquitecturas y entornos urbanos con el despliegue de numerosas actividades complementarias, más ricas y variadas que las habituales de estos conjuntos en las exposiciones contemporáneas, pues, junto con los tradicionales puestos de venta de recuerdos o los restaurantes con comidas "típicas", se organiza un buen número de muestras de artesanía, exposiciones de arte, fiestas, actuaciones musicales, concursos..., hasta corridas de toros. La parcela más formativa del proyecto expositivo se enriquece con la instalación de un buen número de dioramas, tanto de temática histórica como geográfica o paisajística.

Tras un tiempo de abandono provocado por la Guerra Civil, en 1942 el Ayuntamiento de Barcelona instala en varios de sus edificios el Museo de Industrias y Artes Populares, tomando como base las colecciones etnográficas pertenecientes al Museo Arqueológico de Barcelona. En 1962 aquél se fusiona con el Museo Etnológico barcelonés y, si bien no abandona físicamente el recinto hasta mucho más $\operatorname{tarde}^{18}$, parece que desde entonces (o poco después) únicamente son visitables algunas colecciones etnográficas y la denominada Casa Pallaresa. Al margen de esta circunstancia,

\footnotetext{
${ }^{17}$ Es muy escasa la bibliografía disponible sobre el Pueblo Español de Barcelona. Afortunadamente, la empresa gestora del recinto editó hace unos años una interesante y densamente ilustrada monografía (Bengoechea 2004).

${ }^{18}$ En 1982 deviene en Museu d'Arts, Indústries i Tradiciones Populars, volviendo a fusionarse con el Etnològic en 1999.
} 
durante las décadas de 1960 y 1970 el conjunto monumental del Pueblo Español asume una doble función como espacio de recreo y territorio de afirmación nacionalista española. Después de varios años de languidez, casi de abandono, en 1986 se hace una concesión administrativa a una empresa privada — vigente inicialmente hasta 2016 y luego ampliada hasta 2036 - para la explotación del recinto, lo que ha supuesto su recuperación y consolidación como "museo arquitectónico" (en palabras de la empresa) y sobre todo como espacio lúdico, aunque también tiene cabida en su seno el desarrollo de muy variadas actividades de carácter cultural. Con todo ello, aunque el Pueblo Español no puede ser considerado un verdadero museo al aire libre, lo cierto es que ha conseguido mantenerse y potenciar su singular condición de síntesis arquitectónica hispana, consolidándose como el más importante (y seguramente el único) ejemplo preservado de recreación urbana histórico-tradicional surgida de una exposición internacional.

\subsection{Francia}

Desde Barcelona, crucemos de nuevo la cercana frontera francesa y retornemos una vez más a París, el epicentro (con permiso de Londres) del universo expositivo durante el siglo XIX, que todavía pretende seguir siéndolo durante las primeras décadas del XX. Al abordar el certamen de 1937 habíamos dejamos aparcado un parto museístico más, que completaba la revisión global del "estudio del hombre» articulada a través del museo colonial creado en 1931 y del renovado museo antropológico que surge de la exposición del 37. Esta tercera pieza es la consagrada al conocimiento de la propia sociedad francesa, muy especialmente del folklore y los modos de vida de sus comunidades rurales. Hablamos del Musée National des Arts et Traditions Populaires (Segalen 2005).

Aunque el origen de sus colecciones se retrotrae hasta una pequeña sección de etnología francesa abierta en 1884 en el antiguo Museo del Trocadero, el diseño y la organización del MNATP responden a unos intereses y a unos objetivos muy diferentes a los de la ciencia del folklore decimonónica. En primer lugar, su creación viene favorecida por un contexto museístico internacional que a finales de los años 20 (y gracias a la actividad de la Oficina Internacional de Museos) trata de potenciar la apertura de museos etnográficos o folklóricos nacionales, sobre todo al aire libre. En segundo, la propia orientación de la exposición del 37 (sobre "artes y técnicas de la vida moderna") y el hecho de que el Frente Popular accediera al gobierno de Francia en 1936 se conjugan para que los organizadores traten de mostrar tanto la Francia "moderna" como su esencia y diversidad tradicionales — su "identidad nacional", en suma-, a través del despliegue de arquitecturas provinciales y, sobre todo, de la creación de un museo nacional de folklore. Aunque finalmente la instalación que se inaugura como parte de la exposición no corresponde a un museo al aire libre, pues se distribuye por unas pocas salas del Palais de Chaillot, la profesionalidad de su director (el gran museólogo George Henri Rivière) hace del centro una institución de referencia internacional, especialmente tras el traslado a su nueva sede del Bois de Boulogne, en una fecha tan avanzada como 1972. Allí se articula por fin la innovadora estrategia museográfica pergeñada por Rivière, con nuevos modelos y sistemas 
expositivos expresamente diseñados para el centro, que en teoría deberían hacer más accesible y "comprometida" la contemplación de las colecciones. Lamentablemente, la estrategia no llegó a funcionar en cuanto que captadora de público: el museo resulta demasiado "frío" (Segalen 2005: 193). Ya desde finales de los años 80 su decadencia es evidente. Cuando cierra sus puertas, en 2005, se encuentra en estado terminal (aunque, como suele ocurrir, no por voluntad propia). Junto con las colecciones francesas del antiguo Musée de l'Homme (otro elegante cadáver que cierra por las mismas fechas), las del MNATP darán forma al futuro Musée des Civilisations de l'Europe et de la Méditerranée, en Marsella, cuya inauguración estaba inicialmente prevista para 2010, luego pospuesta para 2013.

\subsection{Portugal}

Vamos a terminar nuestro repaso expositivo-museístico en un entorno "periférico", en Portugal, estudiando además un certamen de exclusivo alcance nacional pero muy significativo. Nos referimos a la Exposição do Mundo Português, que tiene lugar en Lisboa en 1940 (Acciaiuoli 1998). El año elegido no es producto del azar, ya que permite conmemorar las dos fechas presuntamente claves de la identidad nacional lusa: el octavo centenario de la "fundación de la nacionalidad" en 1140 y el tercero de la recuperación, en 1640, de la independencia perdida frente a España en 1580. En este exaltado contexto nacionalista y en pleno apogeo económico y cultural del régimen salazarista, el doble objetivo que pretenden alcanzar sus organizadores es muy evidente: en primer lugar, "devolver la confianza" al pueblo portugués a través de la reivindicación de su "glorioso pasado" y de sus esencias nacionales; en segundo, hacerle saber que su "misión en el mundo" aún no ha concluido, pues tiene frente a sí todo un imperio ultramarino para civilizar y modernizar.

Levantada en el barrio lisboeta de Belém, entre los dos monumentos más representativos de la expansión ultramarina lusa (el monasterio de los Jerónimos y la Torre de Belém), la exposición ocupa una superficie muy respetable, sobre todo teniendo en cuenta su condición estrictamente nacional, pues se extiende sobre quinientos sesenta mil metros cuadrados. Aunque la única participación extranjera que se admite es la de Brasil, el certamen reproduce todos los elementos propios de una exposición internacional. Así, hay pabellones de temática comercial e industrial, una importante sección colonial, un parque de atracciones y un espacio de diversiones náuticas con la reproducción de un galeón. No obstante, es el referente histórico-simbólico nacional el eje que vertebra el evento, y esto se logra gracias a la construcción de unos impactantes pabellones dedicados a la formación y la independencia nacionales, y a la expansión ultramarina lusa. Pero aún queda un tercer elemento del entramado nacionalista que, al igual que en otros certámenes europeos contemporáneos, tiene amplia proyección en la exposición: las artes y las tradiciones populares. De este modo, los responsables del certamen portugués levantan un "Centro Regional" que tiene como uno de sus principales reclamos la puesta en marcha de muy diversas actividades de cara al público, especialmente los talleres artesanales, los desfiles y las exhibiciones folklóricas con participación de decenas de figurantes. Aunque el espacio exhibidor se articula en torno a la recreación de tres aldeias portuguesas, la dife- 
rencia más intensa que se observa en relación con una creación similar, el Pueblo Español de 1929, la encontramos en que el certamen lisboeta integra un proyecto museográfico de marcado carácter académico, que desemboca en la instalación de una interesante "Sección de la Vida Popular". En principio, su carácter es tan efímero como el resto de la exposición. No obstante, tras varios proyectos museográficos reconducidos y las necesarias reformas y adaptaciones del edificio, las colecciones exhibidas acaban dando origen, en 1948, al Museo de Arte Popular.

Como el conjunto de la exposición, la citada sección dedicada a la "vida popular" está fuertemente ideologizada, presentando un Portugal eminentemente rural, sin miserias ni luchas, pleno de armonía y auténtico núcleo generador de todas las esencias patrias $^{19}$. Desde una perspectiva museográfica, la propia exposición original de 1940 resulta tremendamente exitosa, pues despliega unas muy ricas colecciones con un atractivo estético indiscutible, sugerentemente ambientadas a través de escenas domésticas, artesanales o laborales. Cuando el museo abre sus puertas en 1948, todo ese despliegue de trajes y artefactos del mundo rural se ve realzado gracias a un sugerente diseño museográfico y, sobre todo, a su instalación en unas salas de exposición amplias, decoradas con impactantes murales que cubren dos tercios de las paredes y que son obra de destacados artistas portugueses. La disposición de las colecciones sigue muy de cerca las técnicas museográficas empleadas en el certamen de 1940, que optan, de un lado, por la reconstrucción depurada de determinados ámbitos escenográficos y, de otro, por zonas de exposición con vitrinas y expositores que permiten una variedad notable de puntos de vista y una circulación fluida del público visitante. El resultado es, así, moderno y atractivo, al margen de las connotaciones ideológicas nacionalistas y ultraconservadoras que le guían, aunque es evidente que al final es mucho más importante el proyecto estético que el estrictamente académico.

Lamentablemente, la modernidad del museo acaba quedando anquilosada con el propio centro, que mantiene su discurso expositivo durante décadas. Ni siquiera la Revolución de los Claveles, en 1974, trae cambios relevantes al museo, que se convierte en ejemplo paradigmático de institución del antiguo régimen. Tras años de languidez, el Museo de Arte Popular cierra en 2006, planeándose su conversión en un "Museo del Mar y de la Lengua Portuguesa". Sin embargo, y tras una intensa campaña de protestas en medios académicos y ciudadanos, en 2009 se decide su reapertura con la antigua denominación, algo que se produce efectivamente en diciembre de 2010, aunque de momento únicamente con una exposición temporal sobre la historia del museo y su diseño de futuro. En teoría, continúan las obras de reforma y ampliación del centro, aunque desconocemos si la actual crisis económica de Portugal permitirá que el proyecto llegue a buen puerto.

\section{COLOFÓN}

La intención de estas páginas ha sido servir de recordatorio sobre las relaciones de filiación existentes entre ciertos museos y algunas exposiciones internacionales,

\footnotetext{
${ }^{19}$ Sobre la manipulación del "arte popular" en las exposiciones y en otras iniciativas impulsadas por el Estado Novo portugués, véase Alves (2007).
} 
nacionales y coloniales. No argumentamos que tales tipologías de centros surjan únicamente o de forma mayoritaria a partir de dichos eventos, pero sí consideramos que el vínculo existe y que no siempre se ha valorado de forma adecuada. También podemos anotar que, debido a su intensa dependencia de factores coyunturales, algunos de estos museos (sobre todo los de orientación colonial o etnológico-colonial) no son capaces de afrontar con éxito la transformación de las circunstancias (ideológicas y geoestratégicas) que hicieron posible su gestación, aunque todo depende en buena medida del talante político del país en el que se desarrollan. Después de la Segunda Guerra Mundial, y tras recuperarse el universo expositivo internacional en Bruselas, en 1958, la asociación parece haberse diluido, al menos en lo que se refiere al surgimiento de museos (etnológicos o de cualquier otro tipo) a partir de exposiciones, aunque sería un atrevimiento por nuestro parte afirmarlo de forma rotunda. Cuestión diferente es la participación de los museos en las exposiciones, algo que resulta muy habitual. En cualquier caso, no podemos olvidar que las exposiciones universales o internacionales han dejado de ser esos eventos fastuosos y trascendentales del XIX y comienzos del XX, y que hace tiempo que existen cauces, estrategias e intereses de muy variada condición para la creación de museos, muy especialmente de etnología y folklore, sin olvidar los nuevos rumbos y los procesos de deconstrucción que se han hecho especialmente notorios durante las dos últimas décadas en la museografía "del otro".

\section{BIBLIOGRAFÍA CITADA ${ }^{20}$}

Acciaiuoli, M. 1998. Exposições do Estado Novo, 1934-1940. Lisboa: Livros Horizonte.

Alves, V. M. 2007. "A poesia dos simples': arte popular e nação no Estado Novo". Etnográfica. Revista do Centro de Estudos de Antropologia Social 11(1): 53-89.

Barringer, T. 1998. "The South Kensington Museum and the colonial project", en Barringer, T. y Flynn, T. (eds.), Colonialism and the Object: Empire, Material Culture and the Museum: 11-27. Londres y Nueva York: Routledge

Bengoechea, S. 2004. Els secrets del Poble Espanyol 1919-2004. Barcelona: Poble Espanyol de Montjuï, S.A.

Bennett, T. 1996 [1988]. "The Exhibitionary Complex", en R. Greenberg, R., Ferguson, B. W. y Nairne, S. (eds.), Thinking about Exhibitions: 81-112. Londres y Nueva York: Routledge.

Dias, N. 1991. Le Musée d'ethnographie du Trocadero (1878-1908). Anthropologie et Muséologie en France. París: Éditions du CNRS.

Findling, J. E. y Pelle, K. D. (eds.). 2008. Encyclopedia of World's Fairs and Expositions. Jefferson y Londres: McFarland \& Company, Inc., Publishers.

Gawarecki, K. y Seybold, S. 2007. "Der Vergangenheit kann man nicht entkommen. Eine koloniale Spurensuche im Übersee-Museum Bremen", en Van der Heyden, U. y Zeller, J. (eds.), Kolonialismus hierzulande. Eine Spurensuche in Deutschland: 317-323. Erfurt: Sutton Verlag.

Hodeir, C. 2002. "Un musée permanent pour une exposition éphémére?», en Viatte, G. y François, D. (dirs.), Le Palais des Colonies. Histoire du Musée des arts d'Afrique et d'Océanie: 23-41. París: Réunion des musées nationaux.

\footnotetext{
${ }^{20}$ Además de la bibliografía que se cita, se han consultado entradas sobre exposiciones y museos en las ediciones en español, francés, alemán e inglés de la enciclopedia virtual Wikipedia, así como las páginas web de los museos estudiados, fácilmente accesibles en Internet a través de cualquier buscador.
} 
L'Estoile, B. de. 2001. "Des races non pas inférieurs, mais différentes': de l'Exposition coloniale au Museé de l'Homme", en Blanckaert, C. (ed.), Les politiques de l'anthropologie. Discours et pratiques en France (1860-1940): 391-473 París: L'Harmattan.

L'Estoile, B. de. 2010 [2007]. Le goût des Autres. De l'Exposition coloniale aux Arts premiers. París: Champs essais - Flammarion.

MacKenzie, J. M. 2010. Museums and Empire: Natural History, Human Cultures and Colonial Identities. Manchester : Manchester University Press.

Mingote Calderón, J. L. 2011. "Museos antropológicos, contextos históricos y sociedad". I Ciclo de Conferências do MAP http://www.map.imc-ip.pt/pt/index.php?s=atalho\&id=122.

Musei. 2007. Musei missionari. Bolonia: EMI della Coop. SERMIS.

Romero de Tejada, P. 1995. "Exposiciones y museos etnográficos en la España del siglo XIX". Anales del Museo Nacional de Antropología II: 11-47.

Sánchez Gómez, L. Á. 2003. Un imperio en la vitrina: el colonialismo español en el Pacífico y la Exposición de Filipinas de 1887. Madrid: Consejo Superior de Investigaciones Científicas.

Sánchez Gómez, L. Á. 2007. "Por la Etnología hacia Dios: la Exposición Misional Vaticana de 1925". Revista de Dialectología y Tradiciones Populares LXII (2): 63-107.

Schneider, G. 1982. "Das deutsche Kolonialmuseum Berlin und seine Bedeutung im Rahmen der preußischen Schulreform um die Jahrhundertwende", en Die Zukunft beginnt in der Vergangenheit. Museumsgeschichte und Geschichtsmuseum (Herausgegeben von den Mitarbeitern des Historischen Museums der Stadt Frankfurt am Main): 155-199. Gießen: Anabas.

Segalen, M. 2005. Vie d'un musée: 1937-2005. París: Éditions Stock.

Stoklund, B. 1994. "The role of the International Exhibitions in the construction of national cultures in the 19th Century". Ethnologia Europaea 24 (1): 35-44.

Thomas, D. (ed.). 2010. Museums in Postcolonial Europe. Londres y Nueva York: Routledge

Wastiau, B. 2000. ExitCongoMuseum: Un essai sur la "vie sociale" des chefs-d'oeuvre du musée de Tervuren. Tervuren: Musée Royal de l'Afrique Centrale.

Wates, A.-L. 2005. Mind Over Matter: A Catholic Ethnology for the Vatican's Ethnographic Collections. Tesis doctoral no publicada presentada en la Universidad de Oxford.

Wynants, M. 1997. Des Ducs de Brabant aux villages Congolais. Tervuren et l'Exposition Coloniale 1897. Tervuren: Musée Royal de l'Afrique Centrale Tervuren.

Zeller, J. 2002. "Das Interesse an der Kolonialpolitik fördern und heben'. Das Deutsche Kolonialmusem in Berlin", en Van der Heyden, U. y Zeller, J. (eds.), Kolonialmetropole Berlin. Eine Spurensuche: 142-149. Berlín: Berlin Edition.

Zerbini, L. 2004. "De l'Exposition Vaticane au Musée Missionaire Ethnologique du Latran", en Prudhomme, C. (dir.), Une appropriation du monde. Mission et missions. XIXe-XXe siècles : 223251. París: Éditions Publisud

Zimmermann, A. 2001. Anthropology and Antibumanism in Imperial Germany. Chicago: The University of Chicago Press

Fecha de recepción: 7 de febrero de 2012

Fecha de aceptación: 14 de enero de 2013 